\title{
Taste thresholds in college-age smokers and nonsmokers
}

\author{
DONALD H. McBURNEY and LAWRENCE J. MOSKAT \\ University of Pittsburgh, Pittsburgh, Pennsylvania 15260
}

\begin{abstract}
Taste detection thresholds were measured for $\mathrm{NaCl}$ and Dulcin and recognition thresholds for $\mathrm{NaCl}$, sucrose, $\mathrm{HCl}$, and $\mathrm{QSO}_{4}$ in college-age smokers and nonsmokers. There were no consistent differences in thresholds for any compound between smokers and nonsmokers.
\end{abstract}

In spite of a widespread belief that smoking diminishes taste sensitivity, the literature on this subject is surprisingly inconclusive. Part of the confusion may arise from a failure to distinguish taste from flavor, which includes smell and other sensations in addition to taste. It is possible that smoking has more effect on smell than on taste and that this contributes to the belief. However, Moncrieff (1957) found that. of four odors tested, only for pyridine, which smells like tobacco, did smokers have higher thresholds.

Of the studies on smoking and taste, some (e.g., Arfman \& Chapanis, 1962; Freire-Maia, 1960) used very few subjects. Some (Martin \& Pangborn, 1970) used substances that would be both gustatory and olfactory stimuli. Others (Pangborn \& Trabue, 1973) used difference thresholds, intensity ratings, and degree of liking rather than the more straightforward detection thresholds. The use of rating of subjective magnitude seems particularly inappropriate because, when sensory thresholds are elevated by adaptation or receptor damage, the intensity of suprathreshold substances may be normal due to recruitment-like effects (e.g., McBurney, 1966).

The present study measured both detection and recognition thresholds in an attempt to assess the possible effect of smoking on taste sensitivity to compounds representing the four taste qualities.

\section{EXPERIMENTS I and II}

\begin{abstract}
Method
Subjects. Subjects were recruited from a college-student population without reference to, or knowledge of, their smoking habits. The subjects were uninformed as to the purpose of the experiment. Their mean age to last birthd ay was 19.5 years. There were no significant differences in age between smokers and nonsmokers in any of the experiments. Any subjects who, when asked at the end of the experiment, admitted to smoking at least four cigarettes per day
\end{abstract}

Requests for reprints should be sent to: Donald H. McBurney, Department of Psychology, University of Pittsburgh, Pittsburgh, Pennsylvania 15260. Experiments I and II were conducted as an undergraduate research project by L.J.M. under the supervision of D.H.McB., and was supported by USPHS Research Grant 5R01 NS07873-07 to D.H.McB. We thank Lauren Lindberg and Edmond Watson for technical assistance in Experiments III and IV. were classified as smokers. There were six smokers and six nonsmokers in Experiment $I$ and six smokers and nine nonsmokers in Experiment II.

Procedure. Upon arrival at the laboratory, the subject was met by a receptionist who asked the subject to remove all objects from his/her shirt pockets, if any, in order to reduce cues as to smoking habits, and then directed the subject to the experimental room. The experimenter for Experiments I and II was a smoker and so would, presumably, be less sensitive to any odors of tobacco from the subject. The experimenter did not ask about smoking habits until the end of the experimental session. The subject sat before a sink. All solutions were screened from the subject's view. Pairs of paper cups, containing approximately $15 \mathrm{cc}$ of water or solution, were presented to the subject. The subject rinsed with deionized water before each trial. The subject was asked to indicate which of the pair contained salt (or Dulcin). The intertrial interval was approximately $20 \mathrm{sec}$. The solutions and the rinse water were spit in to the sink.

Solutions. All solutions were made in deionized water, resistance $2 \times 10^{6} \mathrm{ohms} / \mathrm{cm}^{3}$. Solutions were reagent-grade $\mathrm{NaCl}$ or Dulcin in $0.1 \log \mathrm{M}$ dilution steps.

Psychophysical method. The up-down-transformed-response method (Wetherill \& Levitt, 1965) was used, as follows. Testing was begun at the same arbitrarily chosen level for all subjects. The concentration of the solution was increased after any error and decreased after two correct responses in a row. This procedure continued until seven reversals had occurred. The (geometric) mean of the concentrations at which the last six reversals took place was taken as an estimate of the $71 \%$ detection point. The subject was given feedback as to the correct response after each trial.

\section{Results}

Experiment I (NaCl). The (geometric) mean threshold for the six smokers was $4.7 \times 10^{-3} \mathrm{M}$ and for the six nonsmokers was $2.0 \times 10^{-3} \mathrm{M}$. This difference is significant at the .05 level $(t=2.53$, $\mathrm{df}=10$ ). The thresholds for smokers are approximately two times those for the nonsmokers.

Experiment II (Dulcin). The mean threshold for the six smokers was $8.9 \times 10^{-6} \mathrm{M}$ and for the nine nonsmokers was $1.2 \times 10^{-5} \mathrm{M}$. This difference was nonsignificant.

\section{EXPERIMENT II}

The differences between the results found with $\mathrm{NaCl}$ and Dulcin suggest that there might be other differences among taste qualities, or among taste compounds, in the effect of smoking on taste thresholds. 
Experiment 111 was designed to test this hypothesis. In order to gain the efficiency possible with the method to be described below, it was necessary to use a recognition procedure rather than the detection procedure used in Experiments I and II.

\section{Method}

The method was the same as in Experiments I and II, with the following differences:

Subjects. The subjects were recruited as in Experiments I and II with two differences. First, the criterion of smoking was raised to 15 cigarettes per day. Those who smoked 1-14 cigarettes per day were put into a category of light smokers. There were 37 nonsmokers, 8 light smokers, and 12 heavy smokers. Second, because few of the subjects. who were volunteering according to the double-blind recruitment procedure, smoked 15 or more cigarettes per day, the last 28 nonsmokers, the last 3 light smokers, and the last 11 heavy smokers were recruited according to their smoking habits. However. the experimenter was expecting equal numbers of heavy smokers and nonsmokers and did not inquire about smoking habits until after the experiment, as previously.

Solutions. Solutions were made of reagent-grade $\mathrm{NaCl}, \mathrm{HCl}$, commercial sucrose, and laboratory-grade $\mathrm{QSO}_{4}$ in $0.1 \mathrm{M} \log$ steps.

Psychophysical method. A forced-choice recognition procedure was used following Collings (1974). On any trial, one of the four qualities was selected randomly. If the quality was identified correctly, the concentration of the compound was reduced by a 0.1 log step on the next trial on which it appeared. If the response was incorrect. the concentration was increased by a $0.1 \log$ step. This method allows efficient collection of recognition thresholds providing there are not large response biases. Differences among smokers and nonsmokers in response biases were not large enough to influence threshold significantly (cf. Table 1 with Green \& Swets. 1966. p. 408). The procedure continued until there were seven reversals from right to wrong or vice versa for each compound. The concentrations at which the last six reversals occurred were averaged to obtain the, recognition threshold.

\section{Results}

The results of Experiment III are shown in Table 2 broken according to heavy smokers ( $>15 /$ day), all smokers, and nonsmokers. Nonsmokers were slightly more sensitive to $\mathrm{QSO}_{4}$ than either heavy smokers or all smokers. However, both all smokers and heavy smokers were slightly more sensitive than nonsmokers to $\mathrm{NaCl}, \mathrm{HCl}$, and sucrose. All differences were small, on the order of a 0.2 log step. A $2 \times 4$ repeated-measure ANOVA was conducted on the data. The between-subjects factor was smoking (all smokers, nonsmokers). The within-subjects factor was compound $(\mathrm{NaCl}, \ldots)$. Neither the smoking main effect nor the Smoking by Compound interaction attained significance. The compound

Table 1

Percentage of Erroneous Responses: Experiment III (Nonsmokers/Heavy Smokers)

\begin{tabular}{lcccc}
\hline Stimulus & Bitter & Sour & Salty & Sweet \\
\hline $\mathrm{QSO}_{4}$ & & $44 / 53$ & $23 / 20$ & $33 / 27$ \\
$\mathrm{HCL}$ & $54 / 49$ & & $25 / 30$ & $21 / 22$ \\
$\mathrm{NaCl}$ & $28 / 31$ & $36 / 32$ & & $36 / 36$ \\
Sucrose & $42 / 31$ & $35 / 53$ & $23 / 17$ & \\
\hline
\end{tabular}

Table 2

Recognition Thresholds for Nonsmokers, Heavy Smokers, and All Smokers: Experiment III

\begin{tabular}{|c|c|c|c|c|c|}
\hline & & $\mathrm{QSO}_{4}^{*}$ & $\mathrm{HCL}^{* *}$ & $\mathrm{NaCl} \nrightarrow$ & Sucrose $†$ \\
\hline $\begin{array}{l}\text { Non- } \\
\text { smokers }\end{array}$ & $\begin{array}{l}\overrightarrow{\mathrm{X}} \\
\sigma \dagger \dagger\end{array}$ & $\begin{array}{l}4.8 \\
.76\end{array}$ & $\begin{array}{l}1.6 \\
.30\end{array}$ & $\begin{array}{l}7.4 \\
.23\end{array}$ & $\begin{array}{l}9.5 \\
.20\end{array}$ \\
\hline $\begin{array}{l}\text { Heavy } \\
\text { Smokers }\end{array}$ & $\begin{array}{l}\overline{\mathrm{X}} \\
\sigma\end{array}$ & $\begin{array}{l}6.4 \\
.35\end{array}$ & $\begin{array}{l}1.3 \\
.32\end{array}$ & $\begin{array}{l}5.6 \\
.20\end{array}$ & $\begin{array}{c}6.2 \\
.16\end{array}$ \\
\hline $\begin{array}{l}\text { All } \\
\text { Smokers }\end{array}$ & $\begin{array}{l}\overline{\mathrm{X}} \\
\sigma\end{array}$ & $\begin{array}{l}5.5 \\
.33\end{array}$ & $\begin{array}{l}1.1 \\
.36\end{array}$ & $\begin{array}{l}6.8 \\
.26\end{array}$ & $\begin{array}{l}6.9 \\
.29\end{array}$ \\
\hline
\end{tabular}

main effect was significant but of no interest because it simply says that different compounds have different thresholds. The same analysis was also conducted on the data for heavy smokers vs. nonsmokers, with the same results.

\section{EXPERIMENT IV}

Because the detection and recognition procedures yielded different results, it was felt necessary to replicate Experiments I and II, since these had used fewer subjects. Experiment IV was identical to Experiments I and II with the following exceptions. Eight smokers and eight nonsmokers were recruited as in Experiments $I$ and II. except that (1) the criterion for smoking was 15 cigarettes per day, as in Experiment III, and (2) the subjects were recruited according to their smoking habits in order to obtain equal numbers (eight) of smokers and nonsmokers. The same subjects were tested on both $\mathrm{NaCl}$ and Dulcin; half were tested first on $\mathrm{NaCl}$.

\section{Results}

$\mathrm{NaCl}$ thresholds were identical for smokers and nonsmokers. Smokers were slightly and nonsignificantly less sensitive to Dulcin than nonsmokers. See Table 3.

\section{DISCUSSION}

These experiments have failed to show any consistent effect of smoking on taste thresholds. Although Experiment I found higher thresholds for $\mathrm{NaCl}$ in smokers, Experiment IV found smokers and nonsmokers to have identical thresholds. Analysis of variance of the combined results of Experiments I and IV for $\mathrm{NaCl}$ showed a nonsignificant effect. Experiment $\mathrm{I}$ found smokers to be slightly, and nonsignificantly, more sensitive to Dulcin than nonsmokers, but Experiment IV found just the reverse to hold.

Experiment III, which employed recognition rather than detection thresholds, found no overall effect of smoking across the four compounds tested, and no significant interaction between smoking and compound. 
Table 3

Recognition Thresholds for Nonsmokers and for Smokers: Experiments I and IV

\begin{tabular}{llccccc}
\hline & & \multicolumn{2}{c}{$\mathrm{NaCl}^{*}$} & & \multicolumn{2}{c}{ Dulcin $\dagger$} \\
\cline { 3 - 4 } \cline { 5 - 7 } & & \multicolumn{2}{c}{ Experiment } & & \multicolumn{2}{c}{ Experiment } \\
& & I & IV & & II & IV \\
\hline Non- & $\bar{X}$ & 2.0 & 2.2 & 1.2 & .86 \\
Smokers & $\left(\log _{10}\right) \sigma$ & .32 & .20 & .29 & .20 \\
Smokers & $\overline{\mathrm{X}}$ & 4.7 & 2.2 & & .89 & 1.4 \\
& $\left(\log _{10}\right) \sigma$ & .19 & .25 & .14 & .21 \\
\hline
\end{tabular}

*Means $\times 10^{-3} M$, tmeans $\times 10^{-5} M$

The results of the present experiments force us to the conclusion that smoking does not have an important effect on taste thresholds in the age group tested. The counterintuitive nature of this conclusion is probably the reason for the relatively large number of experiments on smoking and taste and their inconclusive results. It is possible that there has been a larger number of experiments conducted than have been reported and that a higher percentage of those finding the expected results have been reported (cf. Gardner, 1966).

Pursell. Sanders, and Haude (1973) have found sucrose sensitivity to be significantly greater in smokers than in nonsmokers. Pursell et al. attribute the greater sweet sensitivity of smokers to reflexive enhancement. This concept seems to have fallen into neglect in the taste literature. As used by Pursell et al.. it appears to refer to various phenomena that today are usually subsumed under simultaneous contrast and successive contrast, the latter including water taste (e.g., McBurney \& Bartoshuk, 1973). The mechanism by which smoking might enhance sweet sensitivity. if true. would be of interest to taste theory because the time course of the effect of smoking on sweet taste is much longer than the usual adaptation situation. In addition, although adaptation to bitter does produce a sweet water taste and potentiates the taste of sweet compounds (McBurney, 1969), no data exist on a possible increase in the ability to discriminate sweet compounds from water as a result of bitter adaptation.

Our conclusions should not be generalized beyond the age group we tested. Kaplan, Glanville, and Fischer (1965) have found that the sensitivity to 6-n-propylthiouracil (a relative of PTC) and quinine decreased with age in smokers but not in nonsmokers. They found no difference between smokers and nonsmokers in the age range of the subjects used in the present study (mean age to last birthday of 19.5 years).

Finally, before any conclusions can be drawn about the effect of smoking on the perception of foods, it will be necessary to study the effects of smoking on smell thresholds and substances that are stimuli for both taste and smell, as Martin and Pangborn (1970) have done.

\section{REFERENCES}

Arfman, B. L., \& Chapanis, N. P. The relative sensitivities of taste and smell in smokers and non-smokers. Journal of General Psychology, 1962, 66, 315-320.

Collings, V. B. Human taste response as a function of locus of stimulation on the tongue and soft palate. Perception \& Psychophysics, 1974, 16, 169-174.

Freire-Maia, A. Smoking and PTC sensitivity. Annals of Human Genetics, $1960,24,333-341$.

GARDNER, R. A. On box score methodology as illustrated by three reviews of overtraining reversal effects. Psychological Bulletin. $1966,66,416-418$.

Green, D. M., \& Swets, J. A. Signal detection theory and psychophysics. New York: Wiley, 1966.

Kaplan, A., Glanville, E., \& Fischer, R. Cumulative effect of age and smoking on taste sensitivity in males and females. Journal of Gerontology, 1965, 20, 335-337.

Martin, S., \& Pangborn, R. M. A note on responses to ethyl alcohol before and after smoking. Perception \& Psychophysics. 1970, 8, 169-170.

MCBurney, D. H. Magnitude estimation of the taste of sodium chloride after adaptation to sodium chloride. Journal of Experimental Psychology, 1966, 72. 869-873.

MCBurney, D. H. Effects of adaptation on human taste function. In C. Pfaffmann (Ed.), Olfaction and taste. New York: Rockefeller University Press, 1969. Pp. 407-419.

McBurney, D. H. \& \& BartoshuK, L. M. Interactions between compounds with different taste qualities. Physiology and Behavior, 1973, 10, 1101-1106.

McBurney. D. H., \& Pfaffmann, C. Gustatory adaptation to saliva and sodium chloride. Joumal of Experimental Psychology, 1963, 65, 523-529.

Moncrieff, R. W. Smoking: Its effect on the sense of smell. American Pertiumer, 1957, 72, 40-43.

Pangborn, R. M., \& Trabue, I. M. Gustatory responses during periods of controlled and ad lib cigarette smoking. Perception \& Psychophysics, 1973. 13. 139.144.

Pursell, E. D., Sanders, R. E., \& Haude, R. H. Sensitivity to sucrose in smokers and nonsmokers: A comparison of TSD and percent correct measures. Perception \& Psychophysics, 1973, 14. 34-36.

Wetherill, G. B., \& LevitT, H. Sequential estimation of points on a psychometric function. British Journal of Mathematical and Statistical Psychology, 1965, 18, 1-10.

(Received for publication September 19, 1973 revision accepted A pril 25, 1975.) 